\title{
El nuevo Museo de la Independencia Colombiana
}

Daniel Castro Benitez / Camilo Sánchez Arango

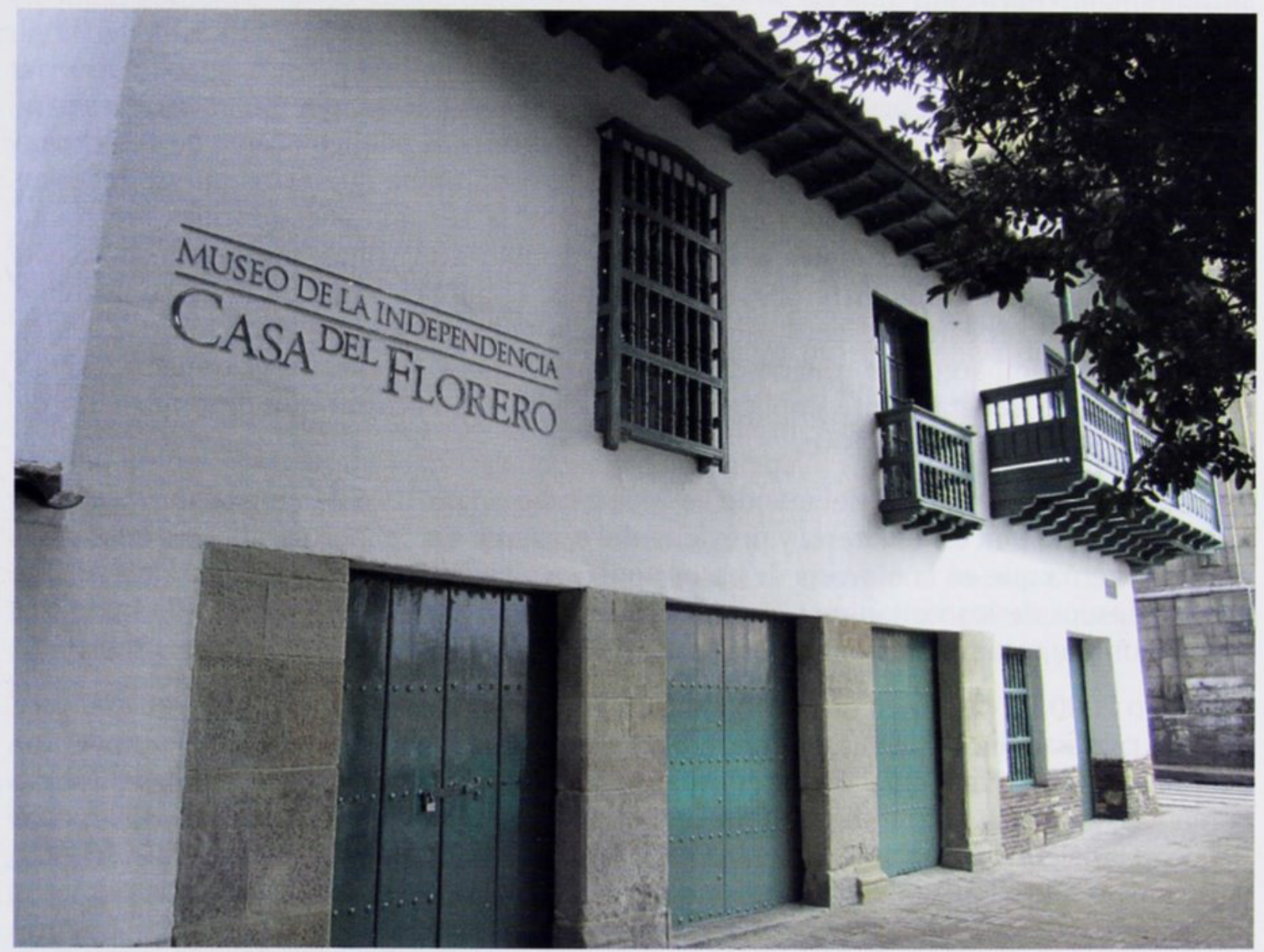

Fig.1. Fachada del Museo después de la restauración

Esta es la historia de cómo un pequeño museo de Bogotá, Colombia, llevó a cabo un proceso de cambio y renovación que, aunque duró casi 10 años, solo se pudo cristalizar con motivo de la conmemoración del Bicentenario de la Independencia Nacional, que se celebró el 20 de julio de 2010.

El eje de las celebraciones bicentenarias se concentró en la tradición histórica de una pequeña casa ubicada en una esquina de la antigua Plaza Mayor, hoy Plaza de Bolívar [Fig. 1], en donde una pelea entre un grupo de criollos y un comerciante español por el préstamo de un florero, produjo una reyerta que derivó en una serie de acciones que nueve años más tarde (7 de agosto de 1819) culminarían con la independencia absoluta de España. 
La casa pasó al olvido y corrió el riesgo de ser destruida y demolida a mediados del siglo XX. Sin embargo en 1960, y para celebrar el Sesquicentenario de la Independencia, los restos de la casa original fueron restaurados por iniciativa de la Academia Colombiana de Historia y del Gobierno Nacional, para albergar un museo dedicado a la fecha del 20 de julio de 1810. Dicha intervención se hizo adicionando al inmueble distintos elementos de otras construcciones coloniales demolidas en el mismo periodo para recrear una casa de estilo andaluz. El resultado, que hubiera hecho palidecer al mismísimo Violet le Duc, es hoy identificado incuestionablemente por el público como una muestra genuina de arquitectura colonial.

Desde su fundación, y hasta el final del siglo pasado, las salas de exhibición no tuvieron cambios significativos y buscaban ser un "libro abierto", siendo cada sala un capítulo de la historia del "Bogotá antiguo" y de la fecha fundacional de la nación colombiana. En consecuencia, el Museo recibió el nuevo milenio como un espacio anacrónico de exclusiva veneración a los héroes patrios y con una mirada tradicional de la historia. Un cambio era absolutamente necesario.

\section{El inicio de la transformación}

Los museos siempre son acusados de ser instituciones obsoletas, que no se mantienen al ritmo de una sociedad cambiante. Cuando se le pregunta al público acerca de sus expectativas de cambio con relación a los museos, la mayoría opina que éstos nunca deberían transformarse, o que el cambio y el progreso debería ser una cuestión más inmediata y "cosmética": decisiones simples que implican cambio de vitrinas, un novedoso diseño gráfico y el uso de nuevos materiales y tecnologías. El público exige un lugar confortable y sobre todo, estéticamente hermoso, una mezcla entre parque de atracciones y centro comercial. Sin embargo, las transformaciones profundas y significativas toman un largo tiempo, porque generalmente implican más un cambio de actitud que de tendencias de exhibición y espacios de disfrute.

Cuando en cualquier museo del mundo se lleva a cabo un proceso de renovación existen al menos dos vías: una es unilateral y proviene del museo y sus "expertos"; la otra busca una mirada externa que en la mayoría de casos convoca a una consulta pública para garantizar que los deseos de los visitantes se vean reflejados en la exposición (después de la cual se acude a un grupo de profesionales que traduzcan estos deseos en acciones concretas).

En el año 2000, se pensó en una reorganización total del Museo y de la forma en que éste debería cambiar. Surgió así una primera propuesta de renovación integral inscrita dentro del primer modelo mencionado anteriormente, en el que el componente fundamental era la renovación de los contenidos del Museo. Mientras que el guión original (de 1960) contaba con las siguientes salas: Sala de la Expedición Botánica, Sala del Florero, Sala del Acta de la Independencia, Sala del periodismo, Sala de la Junta Suprema, Sala de los primeros mandatarios, Galería Iconográfica de los signatarios del Acta, Sala de las Heroínas, Sala del Libertador y de Santander, Oratorio a la Virgen de Chiquinquirá y finalmente, Sala Caldas y Camilo Torres, la nueva propuesta, aunque denotaba un cambio en la organización general del Museo y en el enfoque expositivo, no representaba un cambio profundo en cuanto a la forma de narrar la historia (seguía siendo estrictamente lineal). Esa propuesta incluía las siguientes salas: Sala de la tienda de Llorente, Sala del acta, Sala de los movimientos juntistas, Sala de las ciudades y el territorio, Sala de las independencias y la primera República, Salón de la Guerra Civil y de las tomas de Santa Fe, Sala del fracaso de la guerra contra realistas y campañas del sur, Sala del Centralismo y Federalismo, Sala de Refuerzo y Oratorio.

Esta primera propuesta coincidió con un cambio en la dirección del Museo en el año 2002, que al hacer el análisis de ésta, consideró que adolecía de una validación pública. Aunque no la descartó inmediatamente, inició un proceso pedagógico de diálogo con el público y expertos en varias disciplinas, que terminaría por reinterpretarla. 
Este proceso pedagógico se llevó a cabo de diversas maneras, motivadas a partir de algunos cuestionamientos: ¿Cómo involucrar a los visitantes de manera activa en lugar de simplemente preguntarles lo que deseaban?, ¿Cómo cambiar las preconcepciones históricas sobre los hechos ocurridos hace 200 años?, ¿Cómo transformar la perspectiva del público acerca del carácter del Museo como templo de la patria?, etcétera.

El Museo adelantó una serie de actividades de carácter académico ${ }^{1}$ (coloquios, talleres, conferencias con expertos), e inició una serie de actividades que buscaban cuestionar al público con el fin de generar una actitud participativa y crítica por parte de éste. Las tradicionales salas del Museo empezaron a ser invadidas por preguntas, actividades pedagógicas y reflexiones sobre la colección, el patrimonio y la independencia como concepto, entre otros.

\section{La transición}

La primera de estas iniciativas concretas fue la creación de un lugar denominado "El espacio independiente" (2003-2008), transformándose una de las salas del Museo en un espacio de actividades que iban desde el cuestionamiento de conceptos básicos en cuanto a la tarea del Museo como guardián del patrimonio ${ }^{2}$, hasta la activación de un "pensamiento independiente" ${ }^{\prime 3}$ por medio de la inserción de temas contemporáneos del ámbito público y privado.

Además de estas actividades, se llevaron a cabo una serie de sencillas exposiciones temporales que fueron abonando el camino para los cambios que vendrían más adelante, al validar propuestas pedagógicas e incentivar otros niveles de investigación y difusión de la colección. Por ejemplo, la exposición denominada "Independencia en el acto" (2005), que abordaba el tema del contexto y contenido del Acta de Independencia permitió que los visitantes redactaran su propia acta de independencia. Así mismo, otra muestra llamada "Rompa usted el Florero, nosotros lo reponemos" (2006), abordó el tema tradición histórica del objeto símbolo de la Independencia colombiana, y del cual solo se preservó una parte, e hizo que los visitantes comprendieran cómo la historia no es una construcción única sino que de la misma manera que el objeto en cuestión, es fragmentaria y parcial. Aquí, los visitantes hacían el ejercicio imaginario de completar la pieza fragmentada. Estas estrategias fueron posteriormente utilizadas en la nueva propuesta museográfica con la certeza de que ya habían sido ejercicios suficientemente validados y efectivos en la práctica.

Así mismo, los resultados de exposiciones temporales que exploraban aspectos más especializados en cuanto a piezas de la colección, como la muestra "Restaurar para el Bicentenario: iHabla el Florero, hable con él!" (2008), fruto de investigaciones realizadas por el Museo y la Facultad de Estudios del Patrimonio de la Universidad Externado de Colombia (Programa de Restauración de Bienes Muebles), se incorporaron de manera natural al nuevo guión museográfico planteado para la reapertura del Museo en 2010.

Paralelamente, en el año 2007 se realizó un proyecto de re-nominación de las salas de exposición que intentó producir nuevos sentidos interpretativos de la exhibición tradicional, identificados con interpretaciones más actualizadas del proceso de independencia

1 2003: Coloquio ¿Todo por un florero? Nuevas representaciones de la Independencia para el siglo XXI. 2004: Diálogos transdisciplinarios I: arte, antropología y religión. 2005: Diálogos transdisciplinarios II: ciencia, historia y filosofia. 2006: Diálogos transdisciplinarios III: Minorías étnicas.

2 En una parte de la sala se exhibían, por ejemplo, una silla original y una copia moderna para preguntarle al público cuál era su opinión acerca del uso de reproducciones en lugar de originales, pregunta que suscitaba toda clase de reacciones a favor y en contra.

3 Era permitido usar uno de los sofás de la colección del Museo bajo la premisa "siente(a)se independiente", que planteaba un juego de palabras entre "sentarse" y "sentirse". 
nacional (reconocimiento más amplio de actores sociales y políticos, e inserción de dicho proceso en un contexto global), entre otros aspectos ${ }^{4}$.

Finalmente, se adelantó durante 2007 y 2008 una consulta pública abierta en diversos escenarios, que sirvió de base para la formulación del nuevo proyecto ${ }^{5}$. Esta iniciativa cerró el ciclo que se había abierto en el año 2002, en el cual se consideró indispensable activar la participación de la ciudadanía como parte integral del proceso de renovación del Museo y responder al mandato constitucional ${ }^{6}$ de valoración y validación ciudadana por medio de un ejercicio participativo.

\section{El nuevo proyecto museológico}

En 2008 se empezó a diseñar un nuevo esquema conceptual del Museo basado en los resultados de las iniciativas citadas anteriormente. A partir de los resultados de la consulta pública, y para terminar de configurar el proyecto, se adelantaron dos mesas de carácter transdiciplinar ${ }^{7}$ en las que participaron historiadores, antropólogos, conservadores, museólogos, museógrafos, artistas, comunicadores sociales, estudiantes y académicos, entre otros $^{8}$.

Como resultado de estas mesas, se planteó un esquema conceptual a largo plazo que a su vez fue sometido a diversos exámenes en una serie de mesas especializadas con arquitectos, historiadores y museólogos, que sirvieron para perfeccionar la propuesta. El resultado más importante del nuevo planteamiento fue la necesidad de presentarle al público dos alternativas de recorrido: la "Ruta de la Independencia" y la "Ruta de la Ciudadanía". Esto

4 Por ejemplo, la sala "Acta de la Independencia" se re-nominó sala "¿Independencia en el Acto?"; la sala "Próceres" pasó a ser la sala "Vecinos y vasallos"; la sala "Heroínas" como sala "Femenina es la Independencia"; y la sala "Junta Suprema" cambió a "Con derecho a opinar".

5420 encuestas. Las respuestas más votadas:

1. ¿Qué cree que el Museo de la Independencia debe representar?

- La historia vista desde los personajes que participaron en ella

- La Colombia de ayer y la Colombia de hoy.

2. ¿Qué esperamos que contenga?

- Información interactiva.

- Relatos de los hechos de la Independencia y sus contextos.

- Más elementos históricos sobre la Independencia y su desarrollo.

3. ¿Cómo lo queremos?

- Interactivo, dinámico y moderno.

- Con mayor cantidad de información y objetos.

4. ¿Quiénes deben estar representados?

- Los personajes que participaron en la Independencia.

5. ¿Qué concepto de independencia debería comunicar?

- El de quienes buscaron la Independencia en 1810.

- La Independencia como libertad de cultos, ideas y expresión.

6. Hemos pensado que el Museo debe llamarse Museo de la Independencia, ¿está de acuerdo?

- SI: $81 \%$ NO: $19 \%$

6 Según la Constitución Política de Colombia de 1991.

7 Este concepto supera una relación tradicional entre disciplinas, pues no jerarquiza sino que reconoce la variedad y la diversidad de aproximaciones y contribuciones en un mismo nivel.

8 Resultados de las mesas transdisciplinarias. El Museo en general debería:

- Ser un foro para la difusión y la discusión de nuevas aproximaciones a la historiografia nacional y para la realización de actos de memoria por parte de grupos minoritarios tales como los desplazados de la violencia.

- Recoger (y dialogar con) las opiniones de su público respecto a sus iniciativas.

- Generar mecanismos de interpelación del público del Museo.

- Crear colecciones temporales de objetos relacionados con el ejercicio de la autonomía ciudadana, la identidad territorial y temas similares.

- Abrir el espectro de la idea de protagonistas.

- Abrir el espectro de los relatos.

- Tener elementos sorpresa: preguntas comprometedoras y críticas acerca del estado actual del legado independentista.

- Incluir intervenciones artísticas críticas.

- Hacer una aproximación sensorial al evento de independencia.

- Incluir la historia de la casa: La casa y la Plaza.

- Exhibir lo que (no) nos han contado.

- Incluir el tema de la conmemoración y celebración en la historia. 
con el fin de generar tensión en el visitante al obligarlo a hacer una elección de recorrido (la independencia es, después de todo, una elección que implica decisión). Estas rutas buscan encontrarse en un espacio central en el que la tensión narrativa alcanza su máximo punto en una sala que presenta al objeto emblemático (el Florero), para luego ingresar en sentido contrario a la ruta que no fue elegida desde un comienzo para así tener el panorama completo de la narración del Museo. La mejor manera de ilustrar esta intención la encontramos en la cinta de Möbius ${ }^{9}$.

Cada una de estas rutas fue asignada a un grupo académico de investigación ${ }^{10}$ que se encargó de analizarlas para proponer cambios y ajustes. Una vez se hicieron las correcciones pertinentes, la propuesta terminada se presentó públicamente en diversos escenarios a nivel nacional e internacional, que sirvieron para validar y terminar de detallarla ${ }^{11}$. La propuesta final, requiere de al menos $2,000 \mathrm{~m}^{2}$ de área, que implican el crecimiento de las salas de exhibición y reservas técnicas, así como el de su planta operativa.

\section{Pico y pala}

Mientras se llevaba a cabo la formulación de la propuesta se adelantaron los estudios técnicos arquitectónicos del inmueble para su restauración por parte del Ministerio de Cultura, ente gubernamental al que pertenece el Museo. Estos concluyeron que además de restaurar los vestigios arquitectónicos de la casa colonial, se requiere demoler la parte del Museo añadida en 1960, para

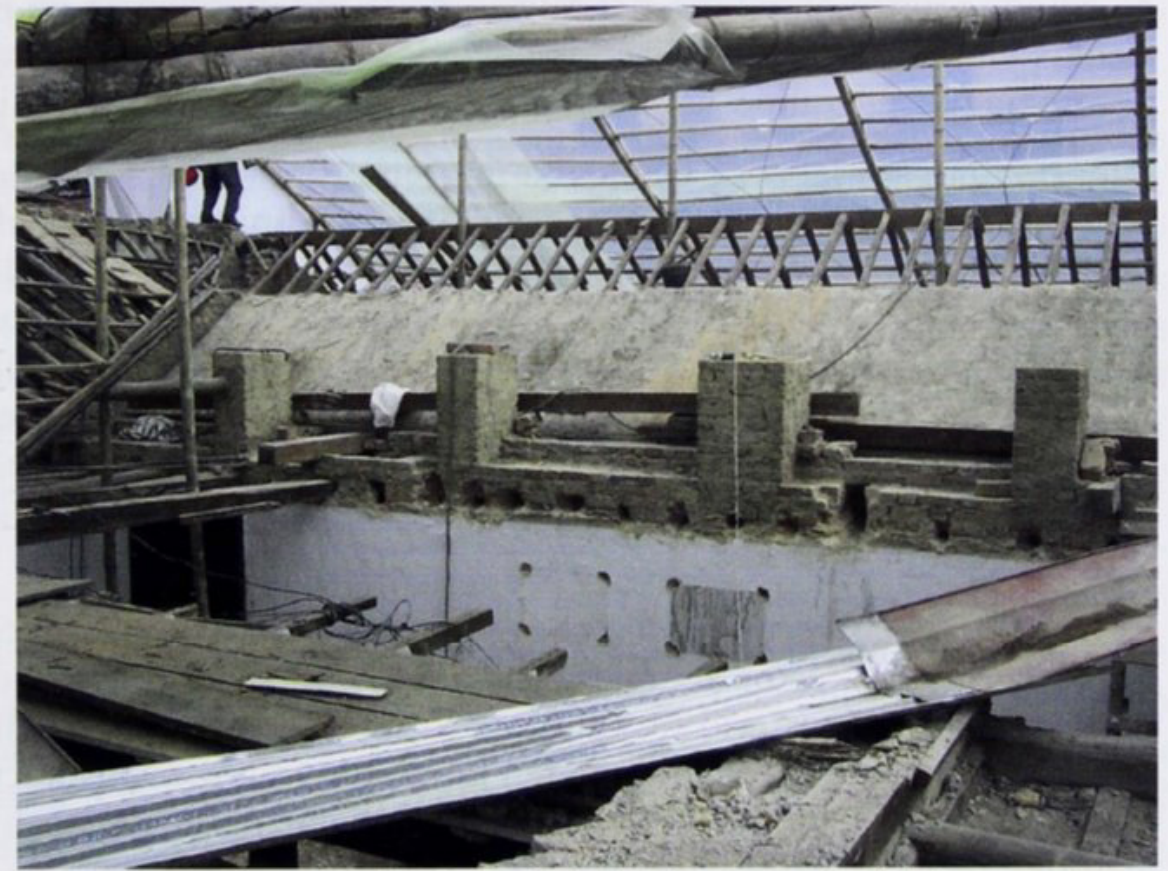

Fig.2. Obra de restauración. Estado de la obra dos meses antes de la inauguración dar lugar a un edificio contemporáneo que le permita al Museo crecer en área de exhibición y ofrecerle al público todos los servicios que éste demanda. Sin embargo, el costo de este proyecto superaba el presupuesto disponible para el Bicentenario y por tal razón se decidió intervenir únicamente la casa original, que además de la readecuación de espacios requería un reforzamiento estructural y antisísmico, y el cambio de nivel en algunas de las cubiertas [Fig. 2].

9 Es una superficie con una sola cara y un solo borde, o componente de contorno, que tiene la propiedad matemática de ser un objeto no orientable, y la cual debe su nombre al matemático alemán August Ferdinand Möbius (1790-1868).

10 Grupo de investigación de la Facultad de Ciencias Sociales y Humanas de la Universidad Externado de Colombia y Grupo de Investigación Ciudadanías de la Universidad Nacional de Colombia.

11 Instancias de validación: Cristina Lleras, curadora de las colecciones de historia del Museo Nacional de Colombia; Facultad de Ciencias Sociales y Humanas de la Universidad Externado de Colombia; Universidad de Los Andes, Departamento de Diseño (Conferencia "Narrativas museográficas"); Antanas Mockus, director de CorpoVisionarios; Asociación Colombiana para el Avance de la Ciencia (IV encuentro de Ciencia y Arte); Intervento, empresa de museografia española; Museo Colonial; Georges Lomné, director del Instituto Francés de Altos Estudios IFEA; Bernardo Tobar, profesor titular de historia de la Universidad Nacional de Colombia; Red Nacional de Museos (Encuentro Nacional de Museos), Maestría en Museología de la Universidad Nacional de Colombia; Seminario Internacional "La museografia de los 3 centavos"(Mayaguiez y Caguas, Puerto Rico); Universidad de Virginia, Congreso de Colombianistas (Charlottesville, Estados Unidos) y Congreso anual de CECA-ICOM (Reikiavik, Islandia). 
Estas decisiones determinaron tres acciones importantes:

- El cierre del Museo durante siete meses para su intervención arquitectónica.

- El embalaje y traslado de toda la colección durante las obras arquitectónicas a un espacio externo al Museo.

- El diseño de una nueva propuesta museográfica limitada a los espacios de la casa original (alrededor de $400 \mathrm{~m}^{2}$ ), lo cual implicó hacer una reducción significativa de los temas planteados en el nuevo proyecto museológico y hacer una pequeña selección representativa de éstos.

\section{El diseño museográfico}

El diseño museográfico se encargó a la compañía brasilera Magnetoscopio, bajo la dirección de Marcello Dantas, quien había recientemente trabajado con mucho éxito en otra propuesta novedosa para un museo ubicado en Barranquilla, zona norte de Colombia, y que se denominó Museo del Caribe. El proceso a seguir fue el resultado de un ejercicio de sinergia entre el equipo del Museo de la Independencia en Bogotá y la compañía de Dantas en San Pablo. Los diseños enviados desde Brasil eran evaluados y aprobados en Colombia por el equipo del Museo de la Independencia y del Ministerio de Cultura.

Mientras por un lado se trabajaba en una propuesta de diseño general, que Marcello presentó al Museo de la Independencia y al Ministerio de Cultura, la obra física presentaba atrasos significativos por falta de planeación y trámites burocráticos. En un proyecto tan complejo como éste, en el que la fecha de apertura era inamovible pues correspondía al momento exacto de la conmemoración bicentenaria ( 20 de julio de 2010) se presentaron muchos problemas por la premura del tiempo, ya que Dantas fue contactado en diciembre de 2009 y la obra de restauración de la casa se inició apenas en enero de 2010. Era definitivamente una carrera contra el tiempo, la historia y el sentido común.

La mayoría de las veces en que se realiza una obra arquitectónica en nuestros países hay retrasos. Además, estos se multiplican dado el carácter público de la institución a la que pertenecemos (Ministerio de Cultura), lo que hace aún más lento cualquier proceso, ya que en muchos aspectos intervienen un gran número de instancias y personas, tanto del ámbito público como privado. Se deben tramitar permisos, realizar convenios, hacer solicitudes técnicas especiales, legalizar contratos, entre muchos otros trámites administrativos. Esto implicó la elaboración de cronogramas que fueron inicialmente de carácter mensual, y poco a poco pasaron a ser semanales e incluso diarios, en los que cada hora del día debía ser aprovechada para cumplir los términos. Esto comprobó que la realidad de la planeación era diferente a la de la ejecución, lo que hizo que se modificaran los tiempos de manera vertiginosa. Ello obligó a que los responsables asumieran una actitud rigurosa pero flexible.

Para resumir, por demoras en los permisos de construcción y otros trámites financieros, la obra, que inicialmente tenía un cronograma de ejecución de seis meses, termino haciéndose solamente en tres, con los sobrecostos que ese recorte de tiempo implicó y con el estrés que trajo consigo.

Volviendo a la parte museográfica, una vez el Ministerio de Cultura y el Museo aprobaron los diseños generales presentados por Dantas, se inició una carrera por darle forma y contenido a lo que se planteaba. Ello condujo a un proceso de producción intelectual que cubrió varios frentes:

- La producción de guiones museográficos y textos específicos para cada sala.

- La selección de piezas a exhibir.

- La cuantificación de todos los elementos museográficos para poder iniciar los procesos de contratación. 
- La generación de guiones para todos los elementos audiovisuales e interactivos, que acarreó una tarea posterior de selección y adquisición de imágenes y videos necesarios para armar el conjunto.

Este último punto fue especialmente traumático, dado que el Museo no estaba acostumbrado al lenguaje y requerimientos técnicos de los productores audiovisuales. Luego de muchas jornadas extenuantes de trabajo con los productores, en las que parecía que no se avanzara en lo más mínimo, ya que la discusión se centraba solamente en la "sensación visual" de los videos e interactivos (sin hablar de sus contenidos), finalmente y con mucho esfuerzo se establecieron todos los parámetros de producción audiovisual. Se inició entonces una maratón de consecución de materiales para poder producir los videos (teniendo en cuenta que para cada minuto de video se exigía una cantidad impensable de imágenes de soporte), lo cual, y en vista de la falta de tiempo, terminó incidiendo en decisiones de producción que a la postre resultaron efectivas. Por ejemplo, en uno de los videos más complejos del Museo, relacionado con el concepto de Ciudadanía, se tomó la decisión final de utilizar animaciones, en lugar de recurrir a imágenes fotográficas, pues no había tiempo de conseguirlas, ni certeza sobre las fuentes.

Al mismo tiempo, se inició la producción museográfica, que implicaba poner a todos los proveedores a hablar un mismo idioma (comenzando por el portuñol) y a entender el proyecto de manera más global, en lugar de que cada uno se encargara solamente de su parte. En este proceso el Museo actuó como intermediario y facilitador de todas esas conexiones en donde por ejemplo, el diseñador gráfico tenía que trabajar con los proveedores audiovisuales (para que el "look" fuera similar en todos los casos); con los impresores (que a su vez tenían que comunicarse con los proveedores de mobiliario) y así sucesivamente; todo con el objetivo de lograr un producto final coherente y uniforme en el menor tiempo posible.

\section{Los resultados}

Finalmente, luego de un mes de desvelos continuos en las etapas de producción y montaje museográfico (que se realizó simultáneamente a la finalización de la obra física), el Museo se reinauguró un día antes de la fecha límite con el consabido acto protocolario. Al día siguiente, y en la celebración del Bicentenario, el Museo finalmente abrió sus puertas al público, que asistió masivamente. Ese día sirvió como termómetro para evaluar los problemas no previstos, las estrategias logísticas y todas las demás eventualidades que son dificiles de pronosticar antes de enfrentarse a los visitantes.

La semana siguiente, el Museo se cerró al público para realizar todos los ajustes necesarios y a la vez, para llevar a cabo una serie de pre aperturas a grupos de público específicos, de especial interés para el Museo. Se llevaron a cabo, en días consecutivos, eventos para todos los obreros (y sus familias) que participaron en la restauración de la casa, los contratistas (y sus familias) que participaron en la producción museográfica, las familias de todos los empleados, funcionarios del Ministerio de Cultura, empleados de todos los museos de Bogotá, docentes y grupos escolares de colegios preinscritos, funcionarios de entidades de apoyo y finalmente, un solo día de descanso antes de abrir de manera permanente al público.

Lo que el público encuentra cuando entra al Museo es una introducción general a la exhibición, en donde se hace referencia al tema de la independencia como un tema absolutamente actual, relativo y universal; alli, hay un panel con variadas citas célebres relativas al concepto de independencia, que van desde Epicuro, pasando por Walt Disney, hasta Bolivar, Napoleón y Bill Clinton, entre otros. Después, a manera de prólogo, hay un espacio denominado Tiempo de Museo, en donde de manera muy sintética se le cuenta al visitante lo que hasta aquí hemos descrito, haciendo claridad al hecho de que en los próximos años el Museo va a seguir cambiando, y que lo que la gente considera un edificio colonial es realmente 


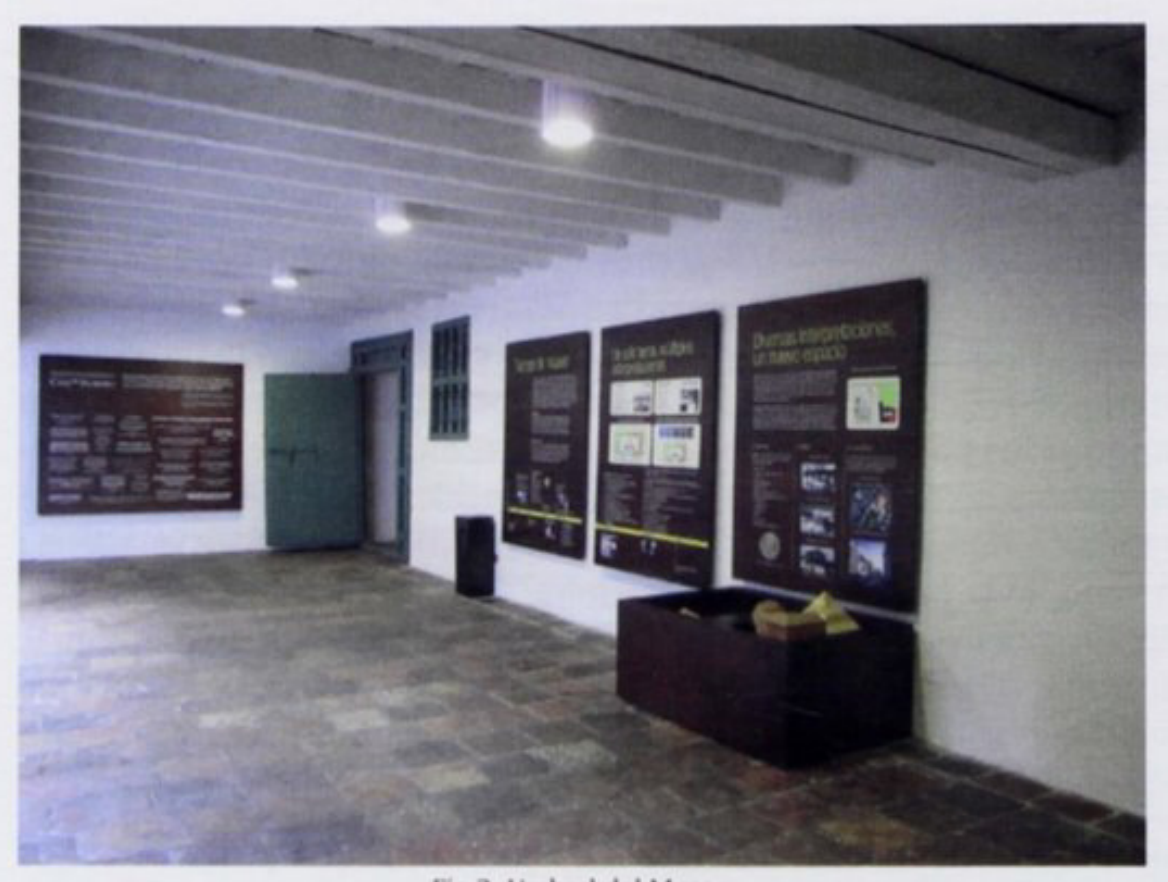

Fig.3. Umbral del Museo un pastiche de los años 60, que espera ser reemplazado por un moderno edificio. Para tal efecto se citan ejemplos internacionales (como el Museo Judío de Berlín, de Daniel Libeskind) e incluso se introdujo un modelo a escala del lote y el edificio para que la gente construya su propio edificio "diferente" a la tradicional casa original [Fig. 3].

En la primera sala, Ilamada Más que criollos

[Fig. 4], el público encuentra una serie de "troncos" (que contienen piezas y videos) que representan diferentes grupos sociales antes de 1810. Este "bosque" está acompañado de un importante cuadro de la época en el que se observa la Plaza Mayor de Bogotá en un día de mercado, momento único en el que todos estos grupos interactuaban de manera directa. Todo esto está acompañado por un cuadro de castas interactivo en el que se muestra que la sociedad neogranadina era precisamente mucho más rica y compleja que el simple binomio de criollos vs. españoles, el cual es un lugar común de la educación básica en Colombia. Este cuadro, que fue construido basándose en cuadros de castas de la Nueva España y Perú, fue sometido a una revisión por parte de Concepción Saiz, directora del

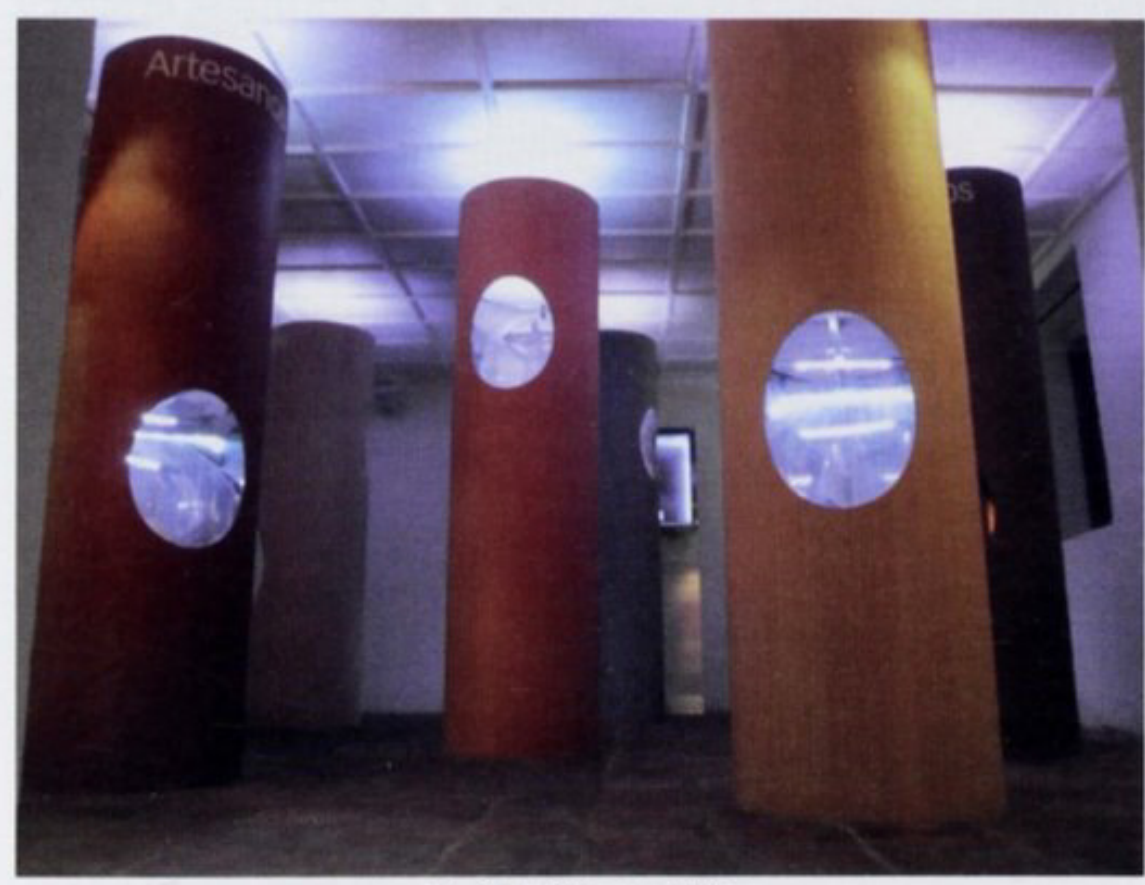

Fig.4 Sala Más que criollos

Museo de América en Madrid, quien hizo acertadas sugerencias que permitieron concretar nuestras ideas.

Después de esto, se entra a una sala llamada La tienda de Llorente, que es una reconstrucción contemporánea (basada en un inventario del comerciante español José González Llorente, a quien le pidieron prestado el famoso florero), en donde se mezclan piezas originales con versiones contemporáneas de productos disponibles en ese mismo espacio, 200 años atrás. Todo se complementa con una pantalla táctil, en ésta los visitantes pueden consultar los precios de los productos de la tienda en 1810 , con una equivalencia a precios de hoy en día, basada en la comparación del jornal de un solda- 
do en 1810 y en la actualidad [Fig. 5].

La siguiente sala, La historia de la casa, la casa en la historia, hace énfasis en la importancia de la ubicación privilegiada de la casa con respecto a la Plaza Mayor, lo cual la ha convertido en protagonista y "espectadora" de los sucesos más importantes de la historia de Colombia. En primera instancia hay una serie de piezas que ilustran el de-

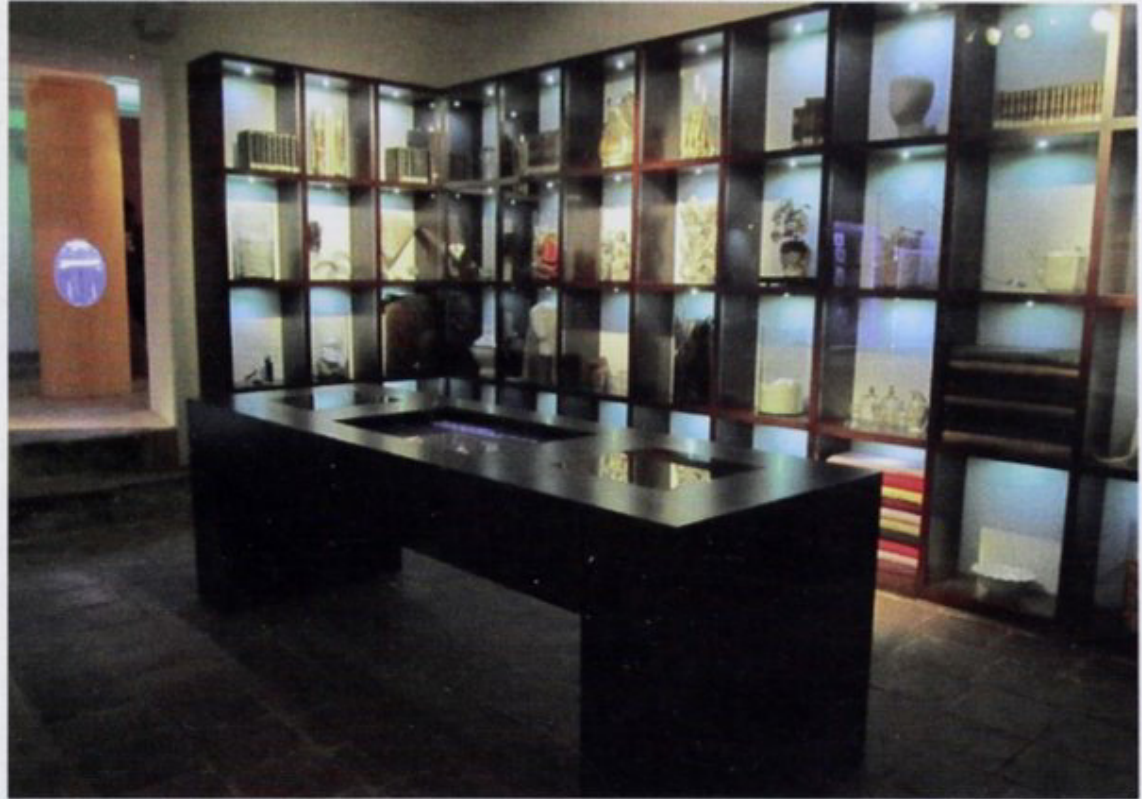

Fig.5. Sala La tienda de Llorente

sarrollo de la casa y los edificios adyacentes, acompañados de una gran maqueta central que se activa con el tacto de los visitantes y en donde el único edificio real es el modelo a escala de la casa; el resto de la Plaza y sus alrededores se proyecta desde el techo por medio de un interactivo que le permite al visitante escoger diferentes periodos históricos, con el fin de ver el cambio que ha sufrido ese espacio neurálgico de la ciudad. Adicionalmente, hay una referencia a los sucesos del 20 de julio de 1810 , contado por medio de retratos de personajes y una serie de animaciones de otras obras de la colección, en la que los personajes hablan y describen qué estaban haciendo en ese momento exacto (dispositivo que ha servido, por ejemplo, para hacer hablar a Bolívar, y permitir que él mismo explique que en ese momento no tenía ninguna relación con la independencia neogranadina, y si por el contrario como diplomático venezolano en Londres) [Fig. 6].

La sala termina con un recuento de dos acontecimientos definitivos para la historia de Colombia en el siglo XX: El asesinato de Jorge Eliecer Gaitán (y los disturbios generados por el pueblo, conocidos como El Bogotazo ${ }^{12}$ ) y la Toma del Palacio de Justicia ${ }^{13}$, tema por demás sensible, ya que no solo la sede

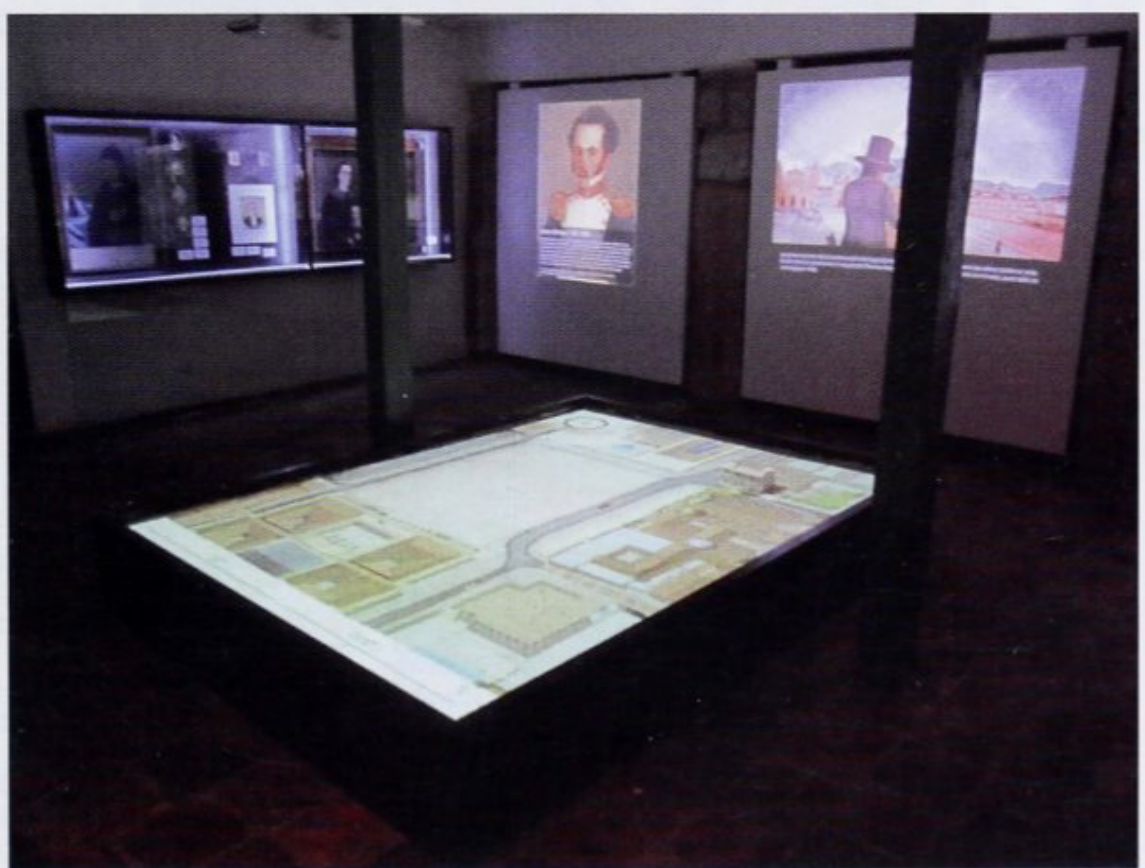

Fig.6. Sala La historia de la casa, la casa en la historia

\section{9 de abril de 1948 .}

13 El 6 y 7 de noviembre de 1985 el grupo guerrillero M-19 se tomó a sangre y fuego las instalaciones del Palacio de Justicia con el fin de llamar a juicio al Presidente de la República por el incumplimiento de los acuerdos de paz que estaban en curso. Ello condujo a una reacción aún más violenta de las Fuerzas Militares, que derivó en el incendio del edificio y la posterior muerte y desaparición de más de un centenar de personas. 


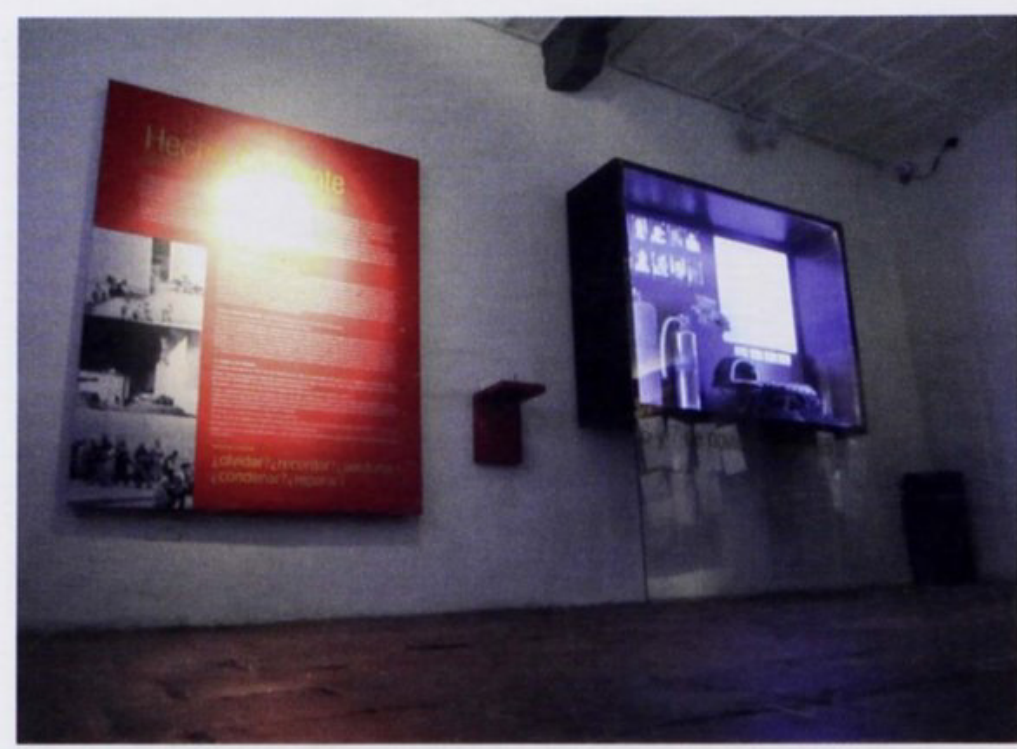

Fig.7. Sala La historia de la casa, la casa en la historia. Sección "Hecho candente" del museo fue usada como central de operaciones para la retoma por parte del Ejército (dada su inmediata vecindad con el Palacio), sino porque sigue siendo un caso judicial no cerrado, en el que por ejemplo, uno de los responsables de la retoma y posterior masacre por parte del Ejército (General Alfonso Plazas Vega) fue condenado a 30 años de cárcel (en primera instancia), quince días antes de la reapertura del museo. Esto causó una airada alocución pública del entonces presidente Álvaro Uribe Vélez, en la que manifestaba no estar de acuerdo con dicha decisión judicial, y que por supuesto, encendió los ánimos y generó zozobra e inquietud, dado que el museo es un ente que pertenece al Estado ${ }^{14}$ [Fig. 7].

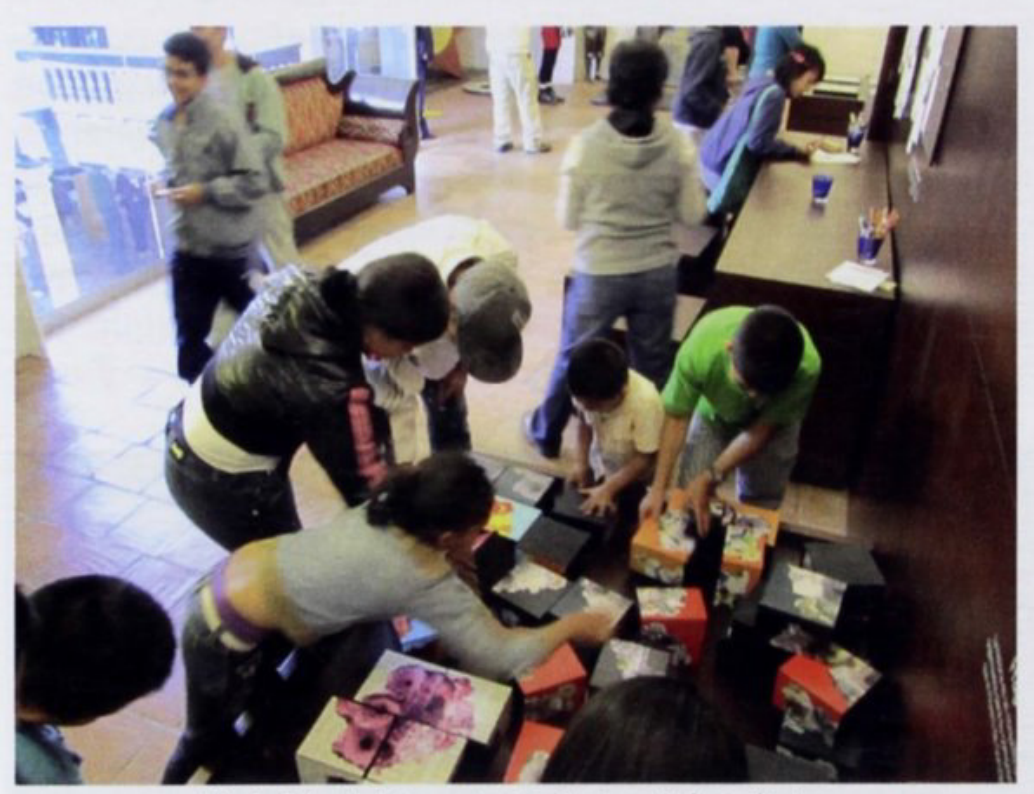

Fig.8. Sala de interpretación Acciones independientes

Antes de entrar a la siguiente sala, el visitante pasa por un espacio de interpretación denominado Acciones independientes, conformado por diferentes módulos que replican ejercicios ya validados y adelantados durante las actividades preparatorias de 2007 y 2008 (firma de actas de independencia personales, silla independiente, rompa el florero, etc.) [Fig. 8].

La sala Contextos de Independencia, que es una síntesis muy pequeña de lo que

14 Para realizar esta aproximación a un evento contemporáneo, el Museo utilizó una estrategia llamada Hot Spot (sensibilización sobre problemas contemporáneos en museos) creada por la Red de Museos Afro-suecos, con quienes nos comunicamos y amablemente nos asesoraron y animaron a aplicar su estrategia. El proyecto Hot Spot se inició en 2001 y se ha implementado en el Museo Mutare en Zimbabwe y en los museos de Malmö y Skelleftea, en Suecia. El proyecto busca desarrollar mecanismos para que los museos puedan tener abordajes sistemáticos a problemas contemporáneos.

Elementos utilizados en el "Hecho Candente":

Un video que presenta imágenes sacadas de material de archivo de noticieros en el momento de la Toma del Palacio de Justicia.

Un panel informativo que muestra cuatro elementos fundamentales: los hechos (en cifras): las motivaciones del grupo guerrillero M-19 (a partir de los comunicados emitidos antes de la operación); las motivaciones del Ejército (sintetizadas en una entrevista dada en el momento de los hechos por el Coronel Plazas Vega); y el llamado de cese al fuego, realizado por Alfonso Reyes Echandía, magistrado y presidente de la Corte Suprema de Justicia, en el momento de la toma.

Una serie de objetos del Holocausto (una máquina de escribir incinerada, un par de extintores con impactos de bala, el casco del Coronel Plazas Vega, etc.).

La lista de personas muertas en el Holocausto.

La lista (con imágenes) de las personas aún "desaparecidas".

Una pregunta al público (¿Olvidar?, ¿Recordar?, ¿Perdonar?, ¿Condenar?, ¿Reparar?), que sirve como mecanismo para registrar y exhibir los sentimientos y opiniones acerca de este hecho. 
va a ser la Ruta de la Independencia planteada en el proyecto museológico previsto, tiene como elemento central un gran telar que representa, por un lado a Europa (con una tela muy fina) $y$ por el otro a América (con una tela un poco más burda). En el medio hay unos hilos que están en proceso de romperse, de separarse. Es esta una metáfora de la historia, en donde si un hilo se mueve en cualquiera

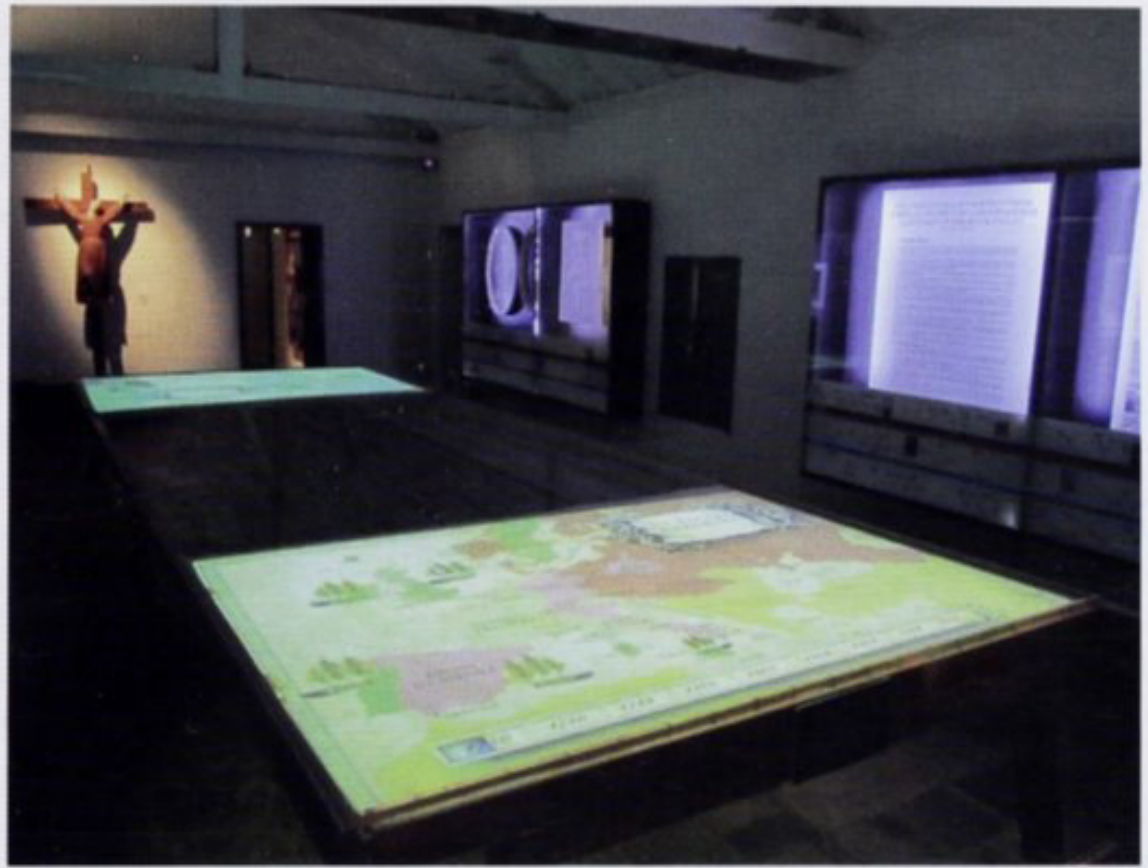

Fig.9. Sala Contextos de Independencia de los extremos, todo el tejido se altera. Sobre cada uno de los lados, el visitante puede consultar, en proyecciones interactivas sobre las telas, diversos aspectos geográficos y políticos que se dieron alrededor de 1810 y que definieron la suerte de ambos continentes, entretejidos en la historia. En el perímetro, se encuentran una serie de vitrinas y una línea del tiempo triple (Colombia, América y Europa) que se extiende desde 1770 hasta el día de hoy, y en donde se señalan acontecimientos históricos relacionados con la independencia, desde los grilletes de Camilo Torres hasta recortes de periódico de 2010, relativos a la existencia de colonias por parte de muchos países, en contravención a la Resolución 1514 (XV) adoptada por la Asamblea General de las Naciones Unidas el 14 de diciembre de 1960: La Declaración de Garantias de Independencia para las Colonias y los Pueblos [Fig. 9].

Llegamos así al espacio central y de mayor tensión: la sala El Florero de Llorente, en donde este importantísimo objeto se encuentra como pieza única, en una vitrina central. Mientras los visitantes entran, bajan unas pantallas y se proyecta en el perímetro un video envolvente (en 3 planos diferentes), se puede ver una serie de expertos y ciudadanos del común que dan su opinión sobre el Florero de Llorente y exponen todo tipo de dudas históricas, interpretaciones y diversas teorías, poniendo al visitante en el centro de una discusión que busca precisamente cuestionar el carácter emblemático de la pieza y el concepto mismo de patrimonio [Fig. 10].

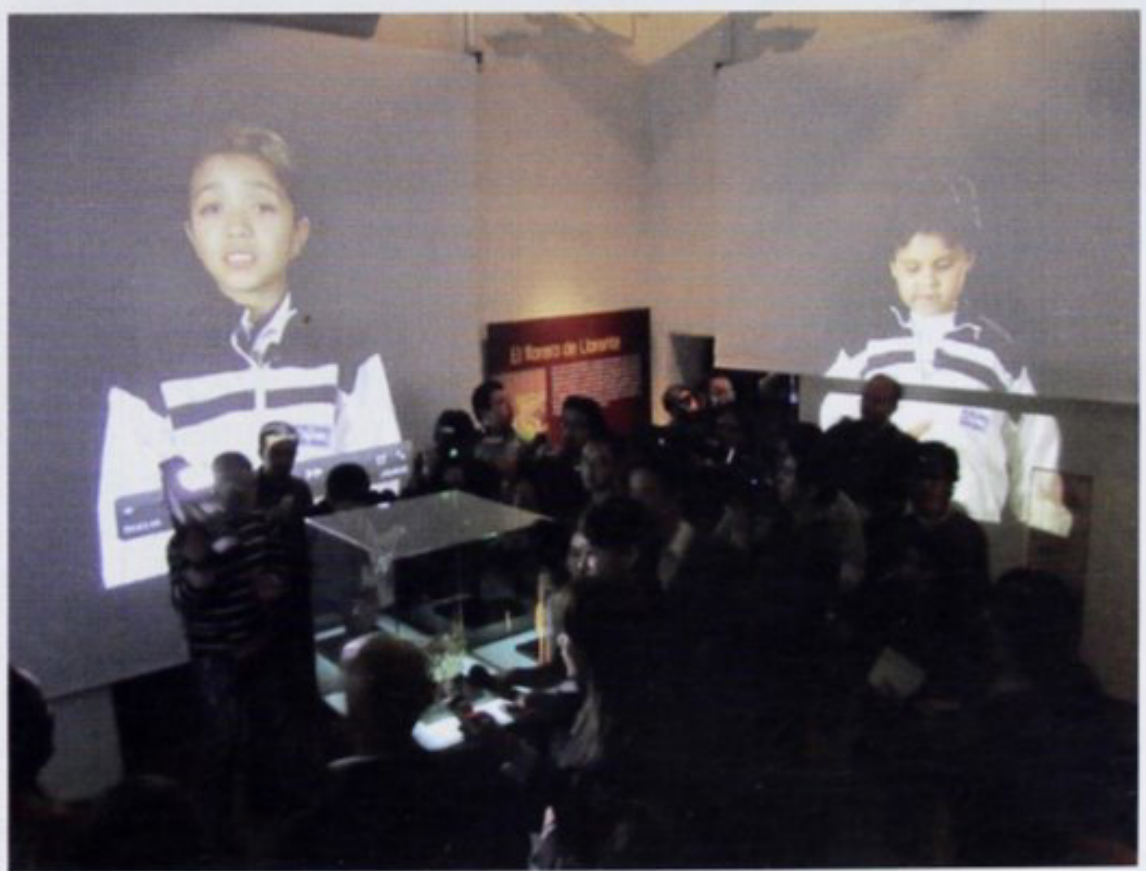

Fig.10. Sala El Florero de Llorente 

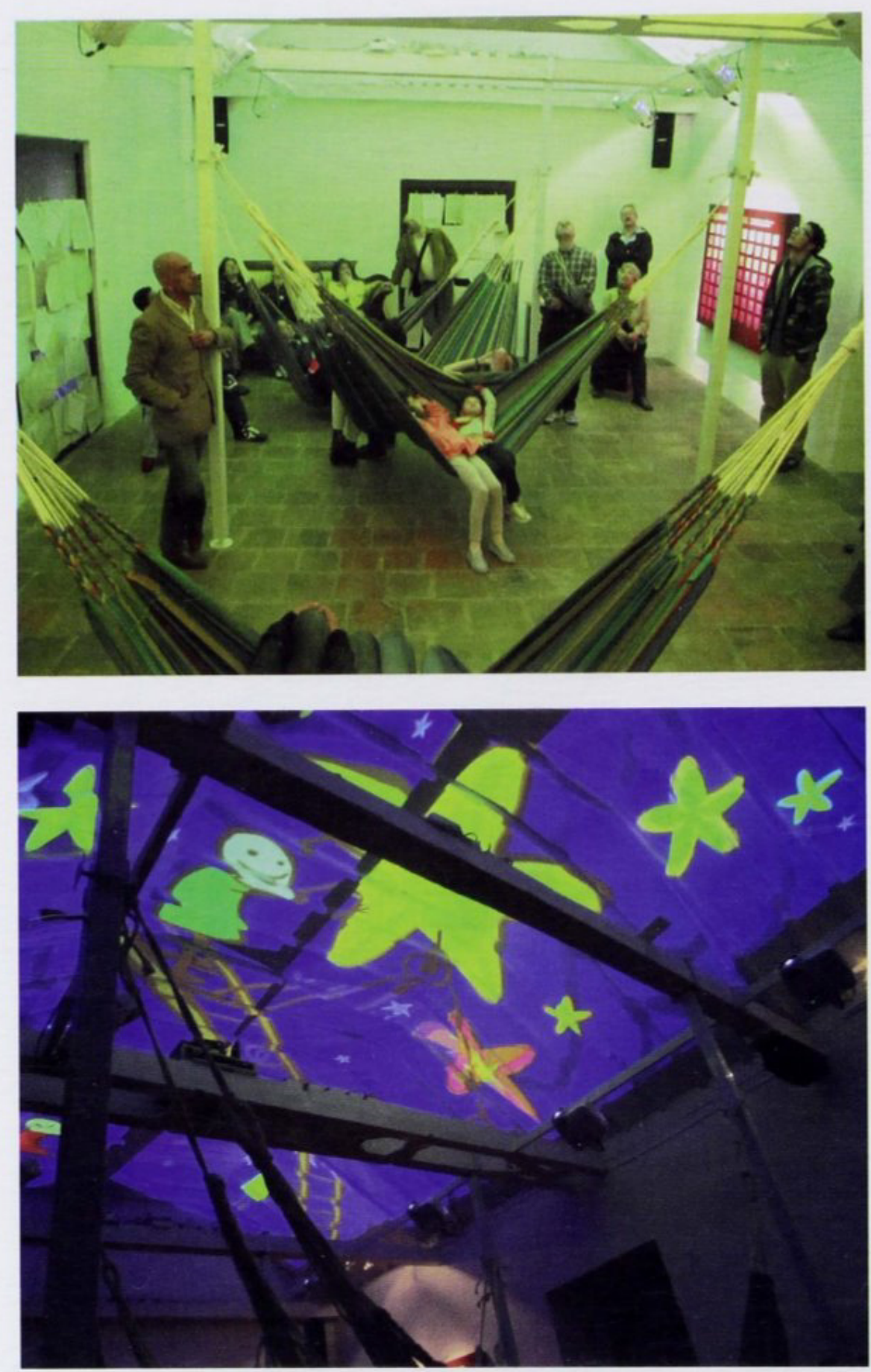

Figs.11 y 12. Sala Legados de Ciudadanía
Una vez terminado el video, los visitantes pasan a la ultima sala denominada Legados de Ciudadanía, allí se pueden sentar en unas hamacas y sillas, que les permiten levantar su mirada y disfrutar de un video proyectado a todo lo largo y ancho del techo, en donde se hace una reflexión sobre el concepto de ciudadanía, indiscutiblemente, el mayor logro y legado del proceso de independencia. Toda la sala está ambientada en sus paredes por bandos y proclamas de la época, y de manera repetitiva, por los Derechos del Hombre y del Ciudadano, traducidos e impresos clandestinamente en Santafé de Bogotá por Antonio Nariño en 1793. Para finalizar, vuelve a aparecer el mismo cuadro de castas de la primera sala con una sutil diferencia, y es que el resultado de todas las mezclas es el mismo: ser ciudadano $^{15}$ [Figs. 11 y 12].

Hoy, los comentarios que recibimos son, en su gran mayoría, muy positivos. Gran parte de los visitantes aceptan la inclusión de dispositivos interactivos y hay una percepción de que es un espacio totalmente nuevo, valorado positivamente como una experiencia enriquecedora y crítica. Sin embargo, obviamente hay gente que se queja por algunos cambios, e incluso hay quienes añoran el viejo museo. Y aquí volvemos a un punto que se comentó al principio de este texto: lo más difícil es cambiar la actitud y comportamiento de parte de los visitantes frente a la idea tradicional de un museo.

15 Las imágenes del resultado final del Museo, se pueden consultar en: http://www.quintadebolivar.gov.co/museoindependencia/index.html

Asi mismo, la exposición temporal "¿Cómo se rehace un museo?", que muestra todo el proceso de renovación del Museo, se puede consultar en:

http://www.quintadebolivar.gov.co/museoindependencia/otrasExposiciones/Comoserehaceunmuseo.pdf 
Quienes se quejan en su mayoría argumentan que la visita no fue guiada (ello nos lleva a deducir que en el fondo se niegan a ser totalmente independientes), otros dicen que ya no hay tantos objetos expuestos como antes (muchos de los cuales fueron cuadros y miniaturas mandadas a hacer "al estilo colonial" en 1960 para llenar vacios en el guión original), e incluso otros tantos lamentan que el área de exhibición fue acortada cuando en realidad se amplió de $331 \mathrm{~m}^{2}$ a $377 \mathrm{~m}^{2}$ a pesar de todas las limitantes presupuestales que se expusieron anteriormente.

Sin embargo, lo más importante para el Museo ha sido la activación de diversos grupos sociales que antes no reparaban en el Museo. Por ejemplo, en noviembre de 2010, el Museo recibió un derecho de petición de los abogados que manejan los casos de las personas desaparecidas en el Palacio de Justicia. Ellos pedían que fuera retirado el casco del General Plazas Vega ${ }^{16}$ de la exhibición porque consideraban que ese objeto no "era digno" de ser exhibido al lado de las fotos de los desaparecidos en la toma, o en su defecto, incluir la sentencia en contra de éste personaje, a lo cual el Museo tuvo que responder de manera negativa, ya que consideraba que la pieza representa a uno de los protagonistas de los hechos y legalmente no podía exhibir la sentencia, ya que ésta se encuentra jurídicamente en su primera instancia.

El proyecto tuvo un costo aproximado de COL \$2,470 millones de pesos (aproximadamente unos US\$1'380,000), repartidos así:

- Estudios arquitectónicos, \$124 millones (aprox. US\$69,000).

- Restauración de la casa, \$1,296 millones (aprox. US\$720,000).

- Diseño museográfico, \$250 millones (aprox. US\$139,000).

- Producción museográfica, \$800 millones de pesos (aprox. US\$450,000).

- El área de exhibición pasó de $331 \mathrm{~m}^{2}$ a $377 \mathrm{~m}^{2}$.

El Museo, que antes se llamaba "Museo del 20 de Julio de 1810" cambió de nombre a "Museo de la Independencia - Casa del Florero", porque más que presentar los hechos ocurridos en Bogotá hace 200 años, busca tratar el tema de la independencia como un concepto actual y no como un hecho cumplido y centrado en una sola fecha. Sin embargo, mantiene la nominación basada en el objeto emblemático de la independencia colombiana. La colección del Museo es de 4,068 piezas, de las cuales están exhibidas 178 del Museo, y 6 del Museo Nacional de Colombia.

Durante el periodo de cierre del Museo, se hicieron actividades educativas externas en un programa denominado "Museo fuera del Museo" y exposiciones itinerantes que llegaron a 39,819 personas.

Cuando se reciben reacciones como ésta (en donde una de las partes afectadas siente que la otra parte no debería ser exhibida, con argumentos como "Aquellos que olvidan su historia están condenados a repetirla..."), la primera reacción es cierto grado de indignación e incomprensión, ya que existe un sinnúmero de argumentos para defender la presentación de todos los actores involucrados en un hecho histórico, haya sucedido hace 200 años o hace escasos 20. Sin embargo, esa incomodidad se convierte en una reacción positiva, porque después de todo, aunque tal vez sea la-manifestación de que al Museo pareciera hacerle falta algo en su mensaje, en el fondo responde a una activación positiva del público, que inclusive, en un momento de inconformidad, recurre a una herramienta legal para luchar por sus derechos, algo que al fin y al cabo, es la esencia del ser ciudadano e independiente.

16 Pieza prestada por el Museo Nacional de Colombia. 
El museo activó al público, y sin lugar a dudas, preferimos recibir comentarios de este tipo cada semana, a no tener reacción alguna frente a todo el esfuerzo realizado.

La definición de un museo como entidad permanente al servicio de la sociedad y su desarrollo plantea una aparente paradoja, a la luz del presente escrito. Hablar de renovación en una institución museal pareciera contradecir su carácter de permanencia, pues parece competir con el imaginario que tiene el común de las personas de lo que debe ser el sentido de una entidad educativa y cultural como un museo: la de una tradición inamovible. Sin embargo, se ha querido demostrar cómo en el contexto de una conmemoración histórica como el Bicentenario de la Independencia colombiana, se hace necesario trabajar en transformaciones, renovación y cambio de los discursos y las formas de comunicar los contenidos históricos, aún en contra de adversidades como los apretados cronogramas, las exigencias de agentes externos, así como los lentos ritmos que genera la burocracia estatal.

Por consiguiente, la gran lección que deja este proceso de renovación integral para el Museo de la Independencia es la siguiente: si un museo se debe a la sociedad en la que está inscrito, y por naturaleza esta sociedad se transforma, el museo está en la obligación de integrar esas transformaciones sociales en su dinámica institucional, contenidos y formas de comunicación. Sólo así tendrá verdadero sentido la comprensión de ios procesos históricos por parte de los ciudadanos a quienes convocamos participativamente y a quienes dirigimos todas nuestras tareas y esfuerzo día tras día. 